\title{
Educación de postgrado en cirugía
}

\author{
Graduate education in surgery
}

El año 2011, ha quedado marcado en nuestra historia como un año de masivas protestas estudiantiles y paros que se han prolongado por más de 7 meses y que han afectado principalmente a alumnos secundarios y universitarios. Las principales razones para estas movilizaciones es el rechazo a la Ley General de Educación promulgada el año 2009, que no satisface a los estudiantes en el sentido de conseguir una mejoría considerable en la calidad, en el acceso y en el financiamiento de la educación. Esta profunda crisis en dicha temática, que está muy lejos de llegar a una solución que satisfaga a la mayoría de la población chilena, sin duda tendrá repercusiones en la formación médica de pregrado y en la formación de postgrado en cirugía que es el área que le compete a nuestra Sociedad de Cirujanos de Chile.

Actualmente, en nuestro país, existen más de 26 Escuelas de Medicina y son 18 las Facultades que forman parte de la Asociación Chilena de Facultades de Medicina (ASOFAMECH). Desde el año 1981 que esta asociación ha cumplido con el rol de ser la Comisión Central de Acreditación de Centros formadores de Especialistas, siendo la encargada de evaluar la calidad de los recursos indispensables para el desarrollo adecuado de un determinado programa de una Facultad de Medicina en el Centro Formador específico. Esta comisión, en forma permanente, fue ajustando sus normas y procedimientos de evaluación desde su fundación hasta su término de actividad en el año 2008. Ese año fue promulgada la Ley de Aseguramiento de la Calidad de la Educación Superior y esta función ejercida por casi 20 años por ASOFAMECH, pasó a una estructura legal que es la CNA (Comisión Nacional de Acreditación). En el caso de los Programas de Especialidades Médicas, en la actualidad la CNA autorizó a la Agencia APICE (agencia de Acreditación de Programas y Centros Formadores de Especialistas Médicos), constituida por representantes de ASOFAMECH, de la Asociación de Sociedades Científicas (ASOCIMED, de la cual participa la Sociedad de Cirujanos de Chile), del Colegio Médico de Chile y un representante de la Academia de Medicina del Instituto de Chile, para tomar la responsabilidad de la acreditación de los programas de especialidades médicas. En este momento ya existen algunos programas de Cirugía General y de especialidades derivadas de la Cirugía acreditados y otros en el proceso de acreditación por parte de APICE. La certificación de los especialistas es realizada por CONACEM (Corporación Nacional Autónoma de Certificación de Especialidades Médicas).

La formación del cirujano es responsabilidad de las Universidades, pero es una labor compartida con otras entidades como el Ministerio de Salud y las sociedades científicas.

\section{Rol de las Universidades}

El aumento explosivo del número de Escuelas de Medicina en nuestro país en los últimos 20 años ha provocado un aumento de la competencia por los campos clínicos, con un desarrollo de la docencia de pregrado de muchas de estas Escuelas, en centros de menor complejidad. El currículo de la carrera de Medicina ha ido reduciendo sus horas dedicadas a la cirugía, lo que también ha influido en la menor preparación que tiene el médico recién egresado, al momento de iniciar su formación de postgrado en las especialidades quirúrgicas.

En los últimos años se ha discutido acerca de la duración que deberían tener los programas de formación en Cirugía General, ya que muchos ven a esta especialidad como un paso para optar a una de las especialidades derivadas de la Cirugía. En Chile, el programa de Cirugía General, dura tres años y en este período el profesional debe lograr los conocimientos, actitudes, habilidades y destrezas para el manejo de la patología quirúrgica general de urgencia y electiva. Se ha planteado reducir el período de formación del cirujano general para favorecer la formación en una sub-especialidad. Este camino parece poco adecuado dada la cada vez menor formación quirúrgica durante el pregrado y la menor posibilidad de cumplir con una frecuencia mínima de intervenciones quirúrgicas durante la formación como cirujano general. En este último punto influye la competencia que se produce por los procedimientos quirúrgicos en el centro formador, con los residentes de las distintas sub-especialidades de la Cirugía. El desarrollo de tecnologías de aprendizaje y adquisición de habilidades en simuladores, ha logrado disminuir en parte este problema. 
EDITORIAL

En Estados Unidos y Europa, la especialidad de Cirugía General está pasando por una crisis, en que se ha observado que son menos los alumnos que escogen a ésta como su primera opción de especialización. Incluso ha habido años como el 2001, en que un 6\% de los cupos ofrecidos, no se lograron llenar. Las razones para esta disminución en el interés por ingresar a realizar dicha especialización son múltiples: largo período de dedicación de 5 años, que puede alargarse a 8 años al incluir la sub-especialización, trabajo excesivo, con mucha responsabilidad y posibilidad de conflictos médico-legales, disminución del ingreso económico comparado con otras especialidades, menor calidad de vida, especialmente para mujeres, que muchas veces deben postergar su maternidad durante el período de formación. También existe un menor incentivo para dedicarse a la Cirugía General y se prefiere una sub-especialidad de menor exigencia laboral y más lucrativa. Esta última tendencia también existe en nuestro país, la que ha sido agravada por el alto costo de la educación universitaria con agobiantes créditos adquiridos por los estudiantes, la existencia de muchos programas de formación autofinanciados y el ingreso de algunas patologías al plan AUGE, que han modificado los ingresos económicos en algunas sub-especialidades.

\section{Rol del Ministerio de Salud (MINSAL)}

El MINSAL provee la mayoría de la infraestructura donde se realiza la formación de especialistas y está a cargo de la contratación de los profesionales y todo el personal que desempeña labores en sus dependencias. Además tiene un rol en regular la necesidad de especialistas que se requieren en el sistema público y participa en el financiamiento de los programas de formación.

\section{Rol de la Sociedad de Cirujanos de Chile (SCCH)}

La SCCH ha tenido un importante rol en la formación continua de nuestros cirujanos. La mayoría de los docentes que trabajan en los centros formadores, son miembros de nuestra Sociedad, los que tienen una destacada participación en las reuniones científicas mensuales de la Sociedad, de sus Departamentos y Capítulos y en el congreso anual. Nuestros miembros representantes forman parte además de las comisiones de acreditación de programas de formación y de la certificación de especialistas. La SCCH trabajó en la propuesta de un "Programa de la especialidad de Cirugía General", publicado en nuestra revista el año 2008. Durante el año 2011 se decidió crear el Departamento de Educación Médica que sin duda impulsará la participación de nuestra Sociedad en la formación del cirujano.

\section{Dr. Mauricio Camus Appuhn Vicepresidente Sociedad de Cirujanos de Chile.}

